\title{
Borderline personality symptoms and work performance: a population-based survey
}

Trees T. Juurlink ${ }^{*}$ (D), Margreet ten Have ${ }^{2}$, Femke Lamers ${ }^{1}$, Hein J. F. van Marle ${ }^{1}$, Johannes R. Anema ${ }^{3}$, Ron de Graaf ${ }^{2}$ and Aartjan T. F. Beekman ${ }^{1}$

\begin{abstract}
Background: This study aims to elucidate the interplay between borderline personality symptoms and working conditions as a pathway for impaired work performance among workers in the general population.

Methods: Cross-sectional data from the Netherlands Mental Health Survey and Incidence Study-2 (NEMESIS-2) were used, including 3672 workers. Borderline personality symptoms were measured with the International Personality Disorder Examination (IPDE) questionnaire. Working conditions (decision latitude, psychological job demands, job security and co-worker support) were assessed with the Job Content Questionnaire (JCQ). Impaired work performance was assessed as total work loss days per month, defined as the sum of days of three types of impaired work performance (inability to work, cut-down to work, and diminished quality at work). These were assessed with the WHO Disability Assessment Schedule (WHO-DAS). Common mental disorders (CMD) were assessed with the Composite International Diagnostic Interview (CIDI).

Results: Number of borderline personality symptoms was consistently associated with impaired work performance, even after controlling for type or number of adverse working conditions and co-occurrence of CMD. Borderline personality symptoms were associated with low decision latitude, job insecurity and low co-worker support. The relationship between borderline personality symptoms and work performance diminished slightly after controlling for type or number of working conditions.

Conclusions: The current study shows that having borderline personality symptoms is a unique determinant of work performance. This association seems partially explained through the impact of borderline personality symptoms on working conditions. Future studies are warranted to study causality and should aim at diminishing borderline personality symptoms and coping with working conditions.
\end{abstract}

Keywords: Borderline personality symptoms, Public health, Employment, Work performance, Occupational health

\section{Background}

Borderline personality disorder (BPD) is a severe mental disorder characterized by impulsivity, emotional instability, interpersonal dysfunction, perturbed self-image and severe functional impairment $[1,2]$. BPD is associated with unemployment, extensive use of social benefits, and therefore high societal costs [2-4]. Ten Have and colleagues [5] found that even minimal borderline personality symptoms are associated with functional impairment and unemployment. Furthermore, Zimmerman and

\footnotetext{
* Correspondence: t.juurlink@ggzingeest.nl

${ }^{1}$ Department of Psychiatry, VU University Medical Centre, Amsterdam Public Health Research Institute, Oldenaller 1, 1081, HJ, Amsterdam, The Netherlands

Full list of author information is available at the end of the article
}

colleagues [6] found that individuals with one borderline personality symptom had significantly more common mental disorders (CMD), psychiatric hospitalizations and missed time from work compared to individuals with no borderline personality symptoms. Extensive, research emphasizes that BPD should be studied as a dimensional construct, because BPD is heterogeneous and trait severity differs [7, 9]. However, little is known about the prevalence of borderline personality symptoms and functioning among those still at work. Studying risk factors for impaired work performance is important, because the costs due to work loss constitute the bulk of total societal costs associated with mental disorders [6]. Furthermore, most people want to work, emphasizing

(c) The Author(s). 2018 Open Access This article is distributed under the terms of the Creative Commons Attribution 4.0 International License (http://creativecommons.org/licenses/by/4.0/), which permits unrestricted use, distribution, and reproduction in any medium, provided you give appropriate credit to the original author(s) and the source, provide a link to the Creative Commons license, and indicate if changes were made. The Creative Commons Public Domain Dedication waiver (http://creativecommons.org/publicdomain/zero/1.0/) applies to the data made available in this article, unless otherwise stated. 
the importance for interventions aimed at improving work performance.

Impaired work performance is often defined as absenteeism (days a worker is absent) and presenteeism (days of reduced functioning while at work) [7]. Potential risk factors of impaired work performance are mental health, such as common mental disorders and personality disorders $[2,7,8]$, and adverse working conditions [9]. The job demands-control model of Karasek is often used for measuring psychosocial working conditions such as decision latitude, psychological job demands, job security and co-worker support [10]. Plaisier and colleagues [11] showed that low co-worker support and low decision latitude were associated with higher absenteeism among workers with and without depressive and anxiety disorders. Vlasveld and colleagues [12] showed that personality characteristics are associated with absenteeism in both healthy workers and workers with depressive and anxiety disorders. We expect that this is also true for workers with borderline personality symptoms and therefore hypothesize that borderline personality symptoms influence work performance and that adverse working conditions will mediate the relationship between borderline personality symptoms and impaired work performance (Fig. 1).

With respect to the working conditions, we expect (i) that borderline personality symptomatology diminishes the experienced decision latitude because individuals with BPD have been shown to experience difficulties in planning, decision-making and controlling their impulses [13, 14]. Difficulties with planning and decision-making might increase feelings of stress. Thus, we hypothesize (ii) that workers with borderline personality symptoms experience

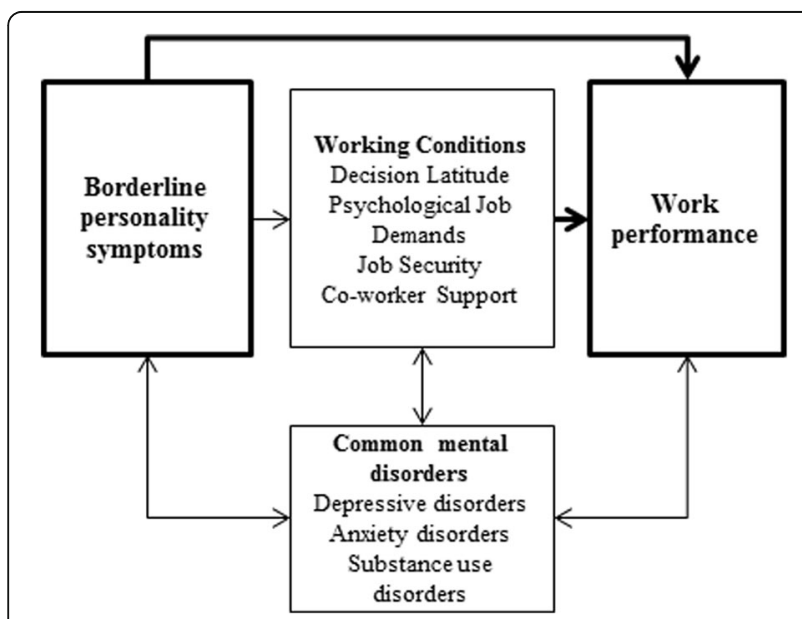

Fig. 1 Proposed model of the interplay between borderline personality symptoms, working conditions and concurrent common mental disorders as a pathway for work performance. Thick arrows indicate direct effect and thin arrows indirect effect. Bidirectional arrows indicate potential confounding variables high psychological job demands. Individuals with BPD were previously found at increased risk for dismissal and demotion [2] and therefore we anticipate (iii) that workers with borderline personality symptoms experience high job insecurity. Interpersonal dysfunction is a key feature of BPD [15] which could lead to conflicts in the workplace [2, 4]. Consequently, we expect (iiii) that workers with borderline personality symptoms will experience low co-worker support.

Borderline personality symptoms often co-occur with common mental disorders (CMD), such as depression and anxiety [5]. These are by themselves associated with absenteeism [16, 17] and presenteeism [7]. Therefore it is important to control for concurrent CMD when studying the interplay between borderline personality symptoms, working conditions on work performance. We used a community based sample from the Netherlands Mental Health Survey and Incidence Study-2 (NEMESIS-2) and aimed to test (i) the association between borderline personality symptoms and impaired work performance, (ii) whether this association was mediated by adverse working conditions and which working conditions are associated with borderline personality symptoms, while (iii) taking the effect of concurrent CMD into account.

\section{Methods \\ Sample}

Data were used from the second wave of NEMESIS-2, in which borderline personality symptoms were assessed and questionnaires on working conditions and work performance were administered. For the present study we selected 3672 participants (1831 men and 1841 women) with a paid job of $>12 \mathrm{~h}$ per week (as in: Ten Have et al. [18]).

NEMESIS- 2 is a nationally representative survey of the general adult population in the Netherlands aged 18 to 64 years $[5,19]$. Participants were selected from households based on multistage, stratified random sampling, selecting one participant per household. In the first wave (T0) from November 2007 to July 2009, a total of 6646 persons were interviewed (response rate 65.1\%; average interview duration: $95 \mathrm{~min}$ ). Although younger participants were slightly underrepresented, the total sample was nationally representative. Interviews were generally held at the participant's home and all interviews were computer-assisted. Three years after T0 from November 2010 to June 2012, participants were approached for follow-up (T1). In this second wave 5303 persons were re-interviewed (response rate $80.4 \%$, those deceased excluded; average interview duration: $84 \mathrm{~min}$ ). Attrition rate was not significantly associated with common mental disorders at baseline, after adjusting for sociodemographic characteristics [20]. For rationale, objectives and 
methods of NEMESIS-2 see De Graaf and colleagues [19]. The NEMESIS-2 study protocol was approved by a medical ethics committee, and all participants provided written informed consent.

\section{Measures}

Borderline personality symptoms were measured using eight questions from the International Personality Disorder Examination (IPDE) [18] corresponding with the DSM symptom criteria for BPD [21]. These questions are part of the Composite International Diagnostic Interview (CIDI) 3.0 - a fully structured lay-administered diagnostic interview [22]. Each question of the IPDE resembles a criterion for BPD [23]. A true-false inventory format was used and the accumulative scores of the total sum of 'true' responses were assessed. The higher the score, the larger the number of borderline personality symptoms. Internal consistency was poor $(\alpha=0.53)$, however this is explained by the variability of the items. The IPDE does not assess one criterion of BPD (recurrent suicidal behaviour, gestures or threats, or self-mutilating behaviour). In a subsample of the $\mathrm{Na}$ tional Comorbidity Survey Replication (NCS-R) in the United States, performing a clinical reappraisal interview, the IPDE was found valid for the assessment of BPD [24].

Working conditions were assessed with the Job Content Questionnaire (JCQ) [25]. Four working conditions were used: decision latitude ( 9 items, $\alpha=0.81$ ), psychological job demands ( 5 items, $\alpha=0.60$ ), job security ( 3 items, $\alpha=$ 0.67 ) and co-worker support ( 4 items, $\alpha=0.79$ ). Response categories were based on 4-point Likert scales ranging from 'strongly disagree' to 'strongly agree', except for two questions on job security that were based on 3-point Likert scales. The number of missing values on each scale was very small, except for co-worker support $(9.1 \%)$ where the missing values were almost all due to workers without colleagues. We kept these missing values and did not redefine them as having no adverse working condition. With respect to borderline personality symptoms, workers without colleagues were not significantly differing in number of borderline personality symptoms compared to those with low or high co-worker support.

Additionally, the number of adverse working conditions was assessed as a measure of job quality consistent with previous studies $[17,24]$. The adverse working conditions were first defined as present on each scale if a score fell in the quartile of the distribution that corresponded to the greatest adversity (e.g. low latitude, high demands, low security and low support). The four adversities were then summed to report the experienced number of adverse working conditions. Missing values on any of the separate working condition adversities, except for low co-worker support, resulted in a missing on the summary measure of number of adverse working conditions $(1.1 \%)$. The measure ranged from 0 to 3 or more adversities and was analysed as an ordinal variable.

Work performance was conceptualized as absenteeism and presenteeism and assessed by three questions on the WHO Disability Assessment Schedule (WHO-DAS) [26]. The questions related to impaired work performance due to illness of the past 30 days and specifically asked the following: (a) "How many days out of the past 30 were you totally unable to work or carry out your normal activities?", (b) "How many days out of the past 30 were you able to work and carry out normal activities, but had to cut down on what you did or not get as much done as usual?" and (c) "How many days out of the past 30 did you cut back on the quality of your work or how carefully you worked?". Total work loss days were based on the sum of days of the three different types of work loss, as previously published [7]. In case of absence for all working days, the two answers on reduced functioning were assigned a value of zero. One day of reduced functioning was counted as half in line with other studies $[24,27]$. The maximum number of lost workdays was set at 21.5 days per month for fulltime workers and proportioned for part-time workers. The following categories were used for analysis: $0,0.1-5$ or $>5.1$ days of work loss.

Presence of CMD was assessed with the CIDI version 3.0, which was developed and adapted for use in the World Mental Health Survey Initiative [22]. An improvement on the Dutch version of the CIDI 3.0 was used in NEMESIS-2. The 12-month disorders include: mood disorder (i.e. major depression, dysthymia and bipolar disorder), anxiety disorders (i.e. panic disorder, agoraphobia, social phobia, specific phobia and generalized anxiety disorder) and substance use disorders (alcohol/drug abuse and dependence). The CIDI 3.0 was found to assess mood, anxiety and substance use disorders with generally good validity in comparison to blinded clinical reappraisal interviews [28].

Next to mood, anxiety and substance use disorders, sex, age, education, and living situation (with or without partner) were considered putative confounders, since these variables are associated with BPD [5]. Mood, anxiety and substance use disorders are furthermore associated with working conditions and work performance [11, 17].

\section{Statistical analyses}

All analyses were performed with STATA version 12.1, using weighted data to correct for differences in the response rates in several sociodemographic groups at both waves and differences in the probability of selection of respondents within households at baseline. Robust standard errors were calculated in order to obtain correct $95 \%$ confidence intervals and $p$-values [29]. 
First, the presence of four categories of number of borderline personality symptoms among this working population were calculated $(0,1-2,3-4$, and $\geq 5$ symptoms). People with $\geq 5$ borderline personality symptoms can be viewed as suffering from BPD, since they fulfil the required number of DSM-IV criteria (at least 5 out of 9) for a BPD diagnosis [30].

Second, the mean number of borderline personality symptoms in sociodemographic characteristics and 12-months common mental disorders were calculated using simple descriptive analyses to study potential confounders.

Third, multivariate linear and multinomial logistic regression analyses were performed to study the association between borderline personality symptoms and type and number of adverse working conditions. In the first series of analyses, adjustments were made for sex and age. In the second series of analyses, additional adjustments were made for education, living situation, any 12 -month mood disorder, any 12-month anxiety disorder, and any 12-month substance use disorder.

Fourth, multivariate multinomial logistic regression analyses were performed to study the association between borderline personality symptoms with work performance. Work performance was categorized as having $0,0.1-5$ or $>5.1$ days of work loss, and the reference category in these analyses consisted of those who reported 0 work loss days in the past month. Again, in the first series of analyses, adjustments were made for sex and age. In the second series of analyses, additional adjustments were made for education, living situation, any 12-month mood disorder, any 12-month anxiety disorder, and any 12-month substance use disorder. In the third series of analyses, the association of borderline personality symptoms and work performance was additionally adjusted for type or number of adverse working conditions to study the association between borderline personality symptoms and work performance mediated by type or number of adverse working conditions. Two-tailed testing procedures were used with 0.05 alpha levels in all analyses.

\section{Results}

\section{Number of borderline personality symptoms}

In this community-based sample of 3672 working people, $72.8 \%$ had no symptoms of borderline personality, $23.8 \%$ had $1-2$ symptoms, $2.7 \%$ had $3-4$ symptoms, and $0.7 \%$ had $\geq 5$ symptoms (mean $0.45(\mathrm{SE}=0.02)$ ) (not in table). Younger age, lower education, living without a partner and the co-occurrence of any CMD were significantly associated with a higher number of borderline personality symptoms (Table 1 ).

\section{Working conditions}

The adjusted associations between borderline personality symptoms and working conditions are summarized in
Table 2. Borderline personality symptoms were associated with less decision latitude, less job security and less co-worker support. These associations persisted after adjustment for sociodemographic characteristics and CMD's (Table 2, Model 2). Higher number of borderline personality symptoms was incrementally associated with poorer job quality, indicated by a higher number of adverse working conditions. The strength of these associations attenuated slightly in the model incorporating all covariates (Table 2, Model 2).

\section{Work performance}

Borderline personality symptoms among workers were associated with impaired work performance, assessed in total work loss days. The mean of total work loss days was $2.0(\mathrm{SE}=0.1)$ (not in table). The number of borderline personality symptoms was consistently associated with impaired work performance, in both categories of work loss (0.1-5 and >5.1 days), also after adjustment for sociodemographic characteristics, CMD and type or number of adverse working conditions (Tables 3 and 4, Model 3).

In the model that included both borderline personality symptoms and each of adverse working conditions separately (Table 3, Model 3), we found that job insecurity was significantly associated with $0.1-5$ work loss days compared to 0 work loss days. Decision latitude, psychological job demands and job security were significantly associated with $>5$ work loss days compared to 0 work loss days, after controlling for sociodemographic characteristics and CMD (Table 3). After additionally controlling for the other types of working conditions and borderline personality symptoms (Table 3, Model 3), the significant association with decision latitude disappeared. Those reporting 3 or more adverse working conditions had higher risk of impaired work performance compared to workers with no adverse working conditions, decreasing slightly per model incorporating more covariates (Table 4, Models 2 and Models 3). Furthermore, in all models the number of borderline personality symptoms was significantly associated with impaired work performance, independent of type or number of adverse working conditions and any concurrent CMD.

\section{Discussion}

To our knowledge, this is the first study examining the interplay between borderline personality symptoms and working conditions as a pathway for work performance in a general population sample. Although the actual number of people with fully developed BPD in the general population is relatively small (in this sample $0.7 \%$ ), the present study shows that lower number of borderline personality symptoms are both common and associated with impaired work performance, independent of the 
Table 1 Sociodemographic characteristics among workers with borderline personality symptoms $(N=3672)$

\begin{tabular}{|c|c|c|c|c|}
\hline & \multicolumn{2}{|c|}{ Total working population } & \multirow{2}{*}{$\begin{array}{l}\text { Borderline personality symptoms (0-6) } \\
\text { Mean }\end{array}$} & \multirow[t]{2}{*}{$P$-value } \\
\hline & $n$ & $\%$ & & \\
\hline Total & 3672 & 100 & 0.45 & \\
\hline Sex & & & & 0.27 \\
\hline Male & 1831 & 56.4 & 0.43 & \\
\hline Female & 1841 & 43.6 & 0.48 & \\
\hline Age & & & & 0.002 \\
\hline $21-37$ & 999 & 36.0 & 0.52 & \\
\hline $38-47$ & 1187 & 29.2 & 0.45 & \\
\hline $48-57$ & 1033 & 25.6 & 0.40 & \\
\hline $58-64$ & 453 & 9.2 & 0.34 & \\
\hline Education & & & & $<0.0001$ \\
\hline Lower secondary & 859 & 24.1 & 0.58 & \\
\hline Higher secondary & 1272 & 42.7 & 0.44 & \\
\hline Higher professional/ University & 1541 & 33.2 & 0.37 & \\
\hline Living situation & & & & $<0.0001$ \\
\hline With partner & 2676 & 71.9 & 0.40 & \\
\hline Without partner & 996 & 28.1 & 0.59 & \\
\hline \multicolumn{5}{|c|}{ Any 12 -month common mental disorder } \\
\hline \multicolumn{5}{|l|}{ Mood disorder } \\
\hline No mood disorder & 3516 & 95.4 & 0.40 & $<0.0001$ \\
\hline Any mood disorder & 156 & 4.6 & 1.59 & \\
\hline \multicolumn{5}{|l|}{ Anxiety disorder } \\
\hline No anxiety disorder & 3486 & 94.0 & 0.41 & $<0.0001$ \\
\hline Any anxiety disorder & 186 & 6.0 & 1.19 & \\
\hline \multicolumn{5}{|l|}{ Substance use disorder } \\
\hline No substance use disorder & 3565 & 96.0 & 0.42 & 0.001 \\
\hline Any substance use disorder & 107 & 4.0 & 1.19 & \\
\hline
\end{tabular}

Significant associations highlighted in bold

type or number of adverse working conditions and concurrent CMD. After adjustment for CMD, the number of borderline personality symptoms was significantly associated with low decision latitude, job insecurity and low co-worker support, however not with psychological job demands.

The low rate of respondents with $\geq 5$ symptoms of borderline personality might be explained by the association between BPD and unemployment or long-term disability benefits $[1,4]$. Furthermore, our findings are based on an epidemiological working population which potentially differs from a clinical population. From this it is conceivable that those with fully developed BPD are more likely to be unemployed than employed [5]. This low prevalence might lead to an underestimation of the contribution of $\geq 5$ borderline personality symptoms to working conditions. We hypothesized that the effect of borderline personality symptoms could contribute to adverse working conditions. As expected, the number of borderline personality symptoms was associated with decision latitude, even after adjustment for CMD. The relation with decision latitude could be explained by difficulties in decision-making and controlling of impulses in persons with BPD $[13,14]$, which may result in feelings of low control.

Contrary to our hypothesis, the association between borderline personality symptoms and psychological job demands was not significant. Despite the association between BPD and higher stress levels both in employment [31] and in general, showing more intense states of aversive tension compared to healthy controls [32]. However, the relation showed an expected increase of psychological job demands, this was not significant.

As anticipated, the number of borderline personality symptoms was associated with job insecurity. Individuals 
Table 2 Borderline personality symptoms as a correlate of working conditions among workers $(N=3672)$

\begin{tabular}{|c|c|c|c|c|}
\hline \multicolumn{5}{|l|}{ Borderline personality symptoms } \\
\hline & $n$ & mean & $\begin{array}{l}\text { Adj. coefficient } \\
{[95 \% \text { Cl] Model } 1}\end{array}$ & $\begin{array}{l}\text { Adj. coefficient } \\
{[95 \% \text { CI] Model } 2}\end{array}$ \\
\hline \multicolumn{5}{|l|}{ Type of working condition } \\
\hline Decision latitude (24-96) & 3661 & 74.25 & $-1.26[-1.75--0.76]$ & $-0.75[-1.26--0.25]$ \\
\hline Psychological job demands (12-48) & 3657 & 30.43 & $0.13[-0.12-0.37]$ & $0.19[-0.08-0.45]$ \\
\hline Job security (3-10) & 3635 & 8.54 & $-0.18[-0.25--0.12]$ & $-0.15[-0.22--0.08]$ \\
\hline Co-worker support (4-16) & 3338 & 12.33 & $-0.09[-0.16--0.02]$ & $-0.07[-0.14--0.002]$ \\
\hline Number of adverse working conditions & $\mathrm{n}$ & $\%$ & $\begin{array}{l}\text { Adj. RRR [95\% Cl] } \\
\text { Model } 1\end{array}$ & $\begin{array}{l}\text { Adj. RRR [95\% Cl] } \\
\text { Model } 2\end{array}$ \\
\hline 0 (optimal) & 1487 & 40.5 & Ref & Ref \\
\hline 1 & 1394 & 38.2 & $1.15[1.02-1.29]$ & $1.08[0.96-1.21]$ \\
\hline 2 & 572 & 16.3 & $1.39[1.21-1.59]$ & $1.29[1.11-1.49]$ \\
\hline 3 or more & 179 & 5.0 & $1.64[1.41-1.90]$ & $1.41[1.19-1.66]$ \\
\hline
\end{tabular}

Adj Adjusted, Cl Confidence interval, RRR Relative Risk Ratios

Ref: Reference category (no adverse working conditions)

Model 1: Adjusted for sex and age

Model 2: Adjusted for sex, age, education, living situation, any 12-month mood disorder, any 12-month anxiety disorder, any 12-month substance use disorder

Significant associations highlighted in bold

with borderline personality symptoms are associated with dismissal and demotion [2,3], which possibly increases the fear of losing a job. Furthermore, data collection took place during times of economic crises, which naturally increases job insecurity. Nevertheless, it is still conceivable that job insecurity also contributes to deterioration of mental health [17].

As expected, borderline personality symptoms were negatively related to co-worker support. Interpersonal problems, which are a core symptom of $\mathrm{BPD}$, are likely to arise as conflicts at work $[2,15,31]$. Individuals with borderline personality symptoms are less capable of reporting accurately on their experiences or on the effect of their behaviour upon others [3, 33]. Moreover, it is conceivable that individuals with borderline personality symptoms underestimate the effect of their behaviour, which can lead to conflicts and less co-worker support. However, the JCQ questions are fairly straightforward and minimise the potential of inaccurately reporting on this working condition.

Table 3 Borderline personality symptoms among workers ( $N=3672)$ and type of working conditions as correlates of impaired work performance

\begin{tabular}{|c|c|c|c|c|c|c|c|}
\hline \multirow[t]{2}{*}{ Work loss days } & \multirow[t]{2}{*}{0 days } & \multicolumn{3}{|l|}{$0.1-5$ days } & \multicolumn{3}{|l|}{$>5.1$ days } \\
\hline & & $\begin{array}{l}\text { Model } 1 \\
\text { Adj. RRR } \\
\text { [95\% CI] }\end{array}$ & $\begin{array}{l}\text { Model } 2 \\
\text { Adj. RRR } \\
{[95 \% \text { Cl] }}\end{array}$ & $\begin{array}{l}\text { Model } 3 \\
\text { Adj. RRR } \\
\text { [95\% CI] }\end{array}$ & $\begin{array}{l}\text { Model } 1 \\
\text { Adj. RRR } \\
{[95 \% \mathrm{Cl}]}\end{array}$ & $\begin{array}{l}\text { Model } 2 \\
\text { Adj. RRR } \\
{[95 \% \mathrm{Cl}]}\end{array}$ & $\begin{array}{l}\text { Model } 3 \\
\text { Adj. RRR } \\
{[95 \% \mathrm{CI}]}\end{array}$ \\
\hline $\begin{array}{l}\text { Borderline personality } \\
\text { symptoms }(0-6)\end{array}$ & Ref & $1.25[1.13-1.38]$ & $1.20[1.08-1.34]$ & $1.14[1.00-1.28]$ & $1.36[1.22-1.51]$ & $1.21[1.07-1.37]$ & $1.16[1.02-1.33]$ \\
\hline \multicolumn{8}{|c|}{ Type of working condition } \\
\hline $\begin{array}{l}\text { Decision latitude } \\
(24-96)\end{array}$ & Ref & $1.00[0.99-1.01]$ & $0.99[0.98-1.01]$ & $1.00[0.99-1.01]$ & $0.98[0.97-1.00]$ & $0.99[0.97-1.00]$ & 0.99 [0.98-1.00] \\
\hline $\begin{array}{l}\text { Psychological job } \\
\text { demands (12-48) }\end{array}$ & Ref & 1.00 [0.98-1.03] & $1.00[0.98-1.02]$ & $1.00[0.97-1.02]$ & $1.04[1.01-1.06]$ & $1.04[1.01-1.06]$ & $1.03[1.00-1.06]$ \\
\hline $\begin{array}{l}\text { Job security } \\
(3-10)\end{array}$ & Ref & $0.85[0.78-0.92]$ & $0.86[0.80-0.94]$ & $0.86[0.79-0.93]$ & $0.83[0.76-0.91]$ & $0.85[0.78-0.94]$ & $0.88[0.80-0.97]$ \\
\hline $\begin{array}{l}\text { Co-worker support } \\
(4-16)\end{array}$ & Ref & $0.97[0.91-1.03]$ & $0.96[0.90-1.02]$ & $0.98[0.92-1.05]$ & $0.95[0.88-1.03]$ & $0.96[0.88-1.05]$ & $1.00[0.92-1.10]$ \\
\hline
\end{tabular}

Adj Adjusted, Cl Confidence interval, RRR Relative Risk Ratios

Ref: Reference category ( 0 days of work loss)

Model 1: adjusted for demographic variables sex and age,

Model 2: adjusted for sex, age, living situation, education and any 12-month mood disorder, any 12-month anxiety disorder and any 12-month substance use disorder,

Model 3: adjusted for model 2 as well as all variables in the column (borderline personality symptoms and the four working conditions).

Significant associations highlighted in bold 
Table 4 Borderline personality symptoms among workers $(N=3672)$ and number of adverse working conditions as correlates of impaired work performance

\begin{tabular}{|c|c|c|c|c|c|c|c|}
\hline \multirow[t]{2}{*}{ Work loss days } & \multirow[t]{2}{*}{0 days } & \multicolumn{3}{|l|}{$0.1-5$ days } & \multicolumn{3}{|l|}{$>5.1$ days } \\
\hline & & $\begin{array}{l}\text { Model } 1 \\
\text { Adj. RRR } \\
\text { [95\% CI] }\end{array}$ & $\begin{array}{l}\text { Model } 2 \\
\text { Adj. RRR } \\
{[95 \% \text { Cl] }}\end{array}$ & $\begin{array}{l}\text { Model } 3 \\
\text { Adj. RRR } \\
\text { [95\% Cl] }\end{array}$ & $\begin{array}{l}\text { Model } 1 \\
\text { Adj. RRR } \\
\text { [95\% CI] }\end{array}$ & $\begin{array}{l}\text { Model } 2 \\
\text { Adj. RRR } \\
\text { [95\% Cl] }\end{array}$ & $\begin{array}{l}\text { Model } 3 \\
\text { Adj. RRR } \\
\text { [95\% Cl] }\end{array}$ \\
\hline $\begin{array}{l}\text { Borderline personality } \\
\text { symptoms }(0-6)\end{array}$ & Ref & $1.25[1.13-1.38]$ & $1.20[1.08-1.34]$ & $1.17[1.04-1.31]$ & $1.36[1.22-1.51]$ & $1.21[1.07-1.37]$ & $1.19[1.04-1.35]$ \\
\hline \multicolumn{8}{|c|}{ Number of adverse working conditions } \\
\hline \multicolumn{8}{|l|}{0 (optimal) } \\
\hline & Ref & Ref & Ref & Ref & Ref & Ref & Ref \\
\hline 1 & Ref & $1.26[0.95-1.68]$ & $1.21[0.89-1.63]$ & $1.20[0.88-1.63]$ & $1.29[0.99-1.70]$ & $1.23[0.93-1.63]$ & $1.22[0.92-1.63]$ \\
\hline 2 & Ref & $1.41[0.97-2.04]$ & $1.43[0.97-2.11]$ & $1.39[0.94-2.05]$ & $1.69[1.16-2.46]$ & $1.54[1.07-2.23]$ & $1.49[1.04-2.15]$ \\
\hline 3 or more & Ref & $2.68[1.55-4.65]$ & $2.49[1.48-4.18]$ & $2.38[1.41-4.01]$ & $2.64[1.64-4.26]$ & $2.21[1.36-3.60]$ & $2.11[1.30-3.43]$ \\
\hline
\end{tabular}

Adj Adjusted, Cl Confidence interval, RRR Relative Risk Ratios

Ref: Reference category ( 0 days of work loss) in the multinomial analyses and in the row ( 0 adverse working conditions)

Model 1: adjusted for demographic variables sex and age,

Model 2: adjusted for sex, age, living situation, education and any 12-month mood disorder, any 12-month anxiety disorder and any 12 -month substance use disorder,

Model 3: adjusted for model 2 as well as all variables in the column (borderline personality symptoms and the four working conditions).

Significant associations highlighted in bold

We found that borderline personality symptoms were associated with impaired work performance, regardless of (adverse) working conditions and concurrent CMD. Our study confirms previous findings that psychopathology is associated with impaired work performance [7] and that higher number of adversities contribute to a deterioration of work performance [18]. Previous studies have shown that BPD is associated with unemployment and long-term disability benefits [1, 4]. Rehabilitation programs to increase skills for those in unemployment might be difficult due to a lack of social context. However, we have studied work performance in workers with borderline personality symptoms still being employed. Our findings show that even workers with few borderline personality symptoms demonstrate impaired work performance. This suggests that programs aimed at increasing work performance might be beneficial for those workers. Furthermore, detecting workers with borderline personality symptoms and increasing their skills in the workplace might prevent from potential long-term unemployment. However, as this is the first study that simultaneously evaluates (adverse) working conditions and borderline personality symptoms on work performance, comparison with other studies was not possible.

Using a population-based approach allowed us to study the associations between borderline personality symptoms and work performance with less risk of selection bias and a greater generalizability than clinical studies. Nevertheless, a number of limitations must be considered. Symptoms of borderline personality were measured with eight questions from the IPDE. Despite evidence that the IPDE was found valid for assessing BPD without the suicidality criterion, this is a limitation since the IPDE is unsuitable for the assessment of BPD in clinical practice. However, the IPDE can be used in epidemiological studies aimed at prevalence and associated correlates [5]. Furthermore, our findings are cross-sectional and, therefore, it is impossible to draw any causal relationships. Although the idea that borderline personality symptoms contribute to adverse working conditions and subsequently impair work performance is plausible, it is also possible that adverse working conditions contribute to an increase in traits, as has previously been shown for CMD [18, 27, 28]. Future studies should address borderline personality symptoms in work performance longitudinally. We were able to test a number of working conditions, however other domains of working conditions may be relevant which we were unable to study. Examples are downsizing in companies, procedural and organizational injustice, exposure to (sexual) violence and threats and role conflicts [34].

\section{Conclusions}

Longitudinal studies are warranted to study the causal relationships between borderline personality symptomatology, working conditions and work performance. The present findings suggest that future studies should examine interventions aimed at diminishing borderline personality symptoms and coping with or changing of working conditions to subsequently reduce impaired work performance. Also, those still in employment are more likely to increase their skills while being in a social context. As previously shown [5, 35], even workers with low numbers of borderline personality symptoms were associated with impaired functioning. This suggests that treatment and research should focus on the broad spectrum of BPD, from lower to higher number of symptoms, both in and out employment. 


\section{Abbreviations}

BPD: Borderline personality disorder; CMD: Common mental disorders; DSM: Diagnostic and Statistical Manual of Mental Disorders

\section{Funding}

NEMESIS-2 is conducted by the Netherlands Institute of Mental Health and Addiction (Trimbos Institute, Utrecht) and additional financial support has been funded by the Ministry of Health, Welfare and Sport, with supplementary support from the Netherlands Organization for Health Research and Development (ZonMw) and the Genetic Risk and Outcome of Psychosis (GROUP) investigators. The funding sources had no further role in study design; in the collection, analysis and interpretation of data; in the writing of the report; or in the decision to submit the paper for publication.

\section{Availability of data and materials}

The data on which this manuscript is based are not publicly available. However, data from NEMESIS-2 are available upon request. The Dutch ministry of health financed the data and the agreement is that these data can be used freely under certain restrictions and always under supervision of the Principal Investigator (PI) of the study. Thus, some access restrictions do apply to the data. The PI of the study is second author of this paper $(\mathrm{MtH})$ and can at all times be contacted to request data.

At any time, researchers can contact the PI of NEMESIS-2 and submit a research plan, describing its background, research questions, variables to be used in the analyses, and an outline of the analyses. If a request for data sharing is approved, a written agreement will be signed stating that the data will only be used for addressing the agreed research questions described and not for other purposes.

\section{Authors' contributions}

All authors contributed to the conception, design and interpretation of analysis for this manuscript. TJ wrote the first draft of the manuscript MtH undertook the analyses. All authors read and corrected draft versions of the manuscript and approved the final manuscript.

\section{Ethics approval and consent to participate}

The study was approved by a medical ethics committee (the Medical Ethics Review Committee for Institutions on Mental Health Care, METIGG). After having been informed about the study aims, respondents provided written informed consent.

\section{Consent for publication}

Not applicable.

\section{Competing interests}

Author JRA is a co-opted member of the guideline authorisation group for the Dutch Occupational Medicine guidelines and is member of the advisory board of the Dutch Board for Occupational Medicine. He is president of the Work disability Prevention and Integration committee of the International Commission on Occupational Health (ICOH). He is chair of the Dutch research Centre for Insurance Medicine. He is chair of the Complaints board for disputes on Pre-employment medical examinations of the Dutch Socio-economic Council. He is editor the international handbook of Work disability is shareholder of Evalua Netherlands LtD stocks. All authors declare they have no competing interests.

\section{Publisher's Note}

Springer Nature remains neutral with regard to jurisdictional claims in published maps and institutional affiliations.

\section{Author details}

'Department of Psychiatry, VU University Medical Centre, Amsterdam Public Health Research Institute, Oldenaller 1, 1081, HJ, Amsterdam, The Netherlands. ${ }^{2}$ Netherlands Institute of Mental Health and Addiction, Trimbos Institute, Utrecht, The Netherlands. ${ }^{3}$ Department of Social Medicine, VU University Medical Centre, Amsterdam Public Health Research Institute, Amsterdam, The Netherlands.
Received: 15 March 2018 Accepted: 6 June 2018

Published online: 19 June 2018

\section{References}

1. Zanarini MC, Jacoby RJ, Frankenburg FR, Reich DB, Fitzmaurice G. The 10year course of social security disability income reported by patients with borderline personality disorder and axis II comparison subjects. J Personal Disord. 2009;23:346-56.

2. Hengartner MP, Müller M, Rodgers S, Rössler W, Ajdacic-Gross V. Occupational functioning and work impairment in association with personality disorder traitscores. Soc Psychiatry Psychiatr Epidemiol. 2014:49:327-35.

3. Cruitt PJ, Boudreaux MJ, Jackson JJ, Oltmanns TF. Borderline Personality Pathology and Physical Health: the role of Employment. Personal Disord Theory Res Treat. 2016;9. https://doi.org/10.1037/ per0000211.

4. Amundsen Ostby K, Czajkowski N, Knudsen GP, Ystrom E, Gjerde LC, Kendler KS, Orstavik RE, Reichborn-Kjennerud T. Personality disorders are important risk factors for disability pensioning. Soc Psychiatry Psychiatr Epidemiol. 2014:49:2003-11.

5. ten Have M, Verheul R, Kaasenbrood A, van Dorsselaer S, Tuithof M, Kleinjan $M$, de Graaf R. Prevalence rates of borderline personality disorder symptoms: a study based on the Netherlands mental health survey and incidence Study-2. BMC Psychiatry. 2016;16:249-59. Available from: http:// bmcpsychiatry.biomedcentral.com/articles/10.1186/s12888-016-0939-x

6. Zimmerman M, Chelminski I, Young D, Dalrymple K, Martinez J. Does the presence of one feature of borderline personality disorder have clinical significance? Implications for dimensional ratings of personality disorders. J Clin Psychiatry. 2012;73:8-12.

7. Morey LC, Berghuis H, Bender DS, Verheul R, Krueger RF, Skodol AE. Toward a model for assessing level of personality functioning in DSM-5, part II: empirical articulation of a core dimension of personality pathology. J Pers Assess. 2011;93:347-53. Available from: http://www.tandfonline.com/doi/ abs/10.1080/00223891.2011.577853

8. Oltmanns TF, Turkheimer E. Person perception and personality pathology. Assoc Pyschological Sci. 2009;18:32-6.

9. Verheul R. Personality disorder proposal for DSM-5: a heroic and innovative but nevertheless fundamentally flawed attempt to improve DSM-IV. Clin Psychol Psychother. 2012;19:369-71.

10. Smit F, Cuijpers P, Oostenbrink J, Batelaan N, de Graaf R, Beekman A. Costs of nine common mental disorders: implications for curative and preventive psychiatry. J Ment Health Policy Econ. 2006;9:193-200.

11. De Graaf R, Tuithof M, Van Dorsselaer S, Ten Have M. Comparing the effects on work performance of mental and physical disorders. Soc Psychiatry Psychiatr Epidemiol. 2012:47:1873-83.

12. Laaksonen M, Pitkäniemi J, Rahkonen O, Lahelma E. Work arrangements, physical working conditions, and psychosocial working conditions as risk factors for sickness absence: Bayesian analysis of prospective data. Ann Epidemiol. 2010;20:332-8.

13. Karasek, R., Theorell T. Healthy work: stress, productivity and the reconstruction of working life. 2nd ed. New York: Basic Books; 1992.

14. Plaisier I, de Graaf R, de Bruijn J, Smit J, van Dyck R, Beekman A, Penninx B. Depressive and anxiety disorders on-the-job: the importance of job characteristics for good work functioning in persons with depressive and anxiety disorders. Psychiatry Res. 2012;200:382-8. Available from: https://doi. org/10.1016/j.psychres.2012.07.016

15. Vlasveld MC, Van Der Feltz-Cornelis CM, Anema JR, Van Mechelen W, ATF B, Van Marwijk HWJ, Penninx BWJH. The associations between personality characteristics and absenteeism: a cross-sectional study in workers with and without depressive and anxiety disorders. J Occup Rehabil. 2012;23:309-17.

16. Bazanis E, Rogers RD, Dowson JH, Taylor P, Meux C, Staley C, NevinsonAndrews D, Taylor C, Robbins TW, Sahakian BJ. Neurocognitive deficits in decision-making and planning of patients with DSM-III-R borderline personality disorder. Psychol Med. 2002;32:1395-405.

17. Rentrop M, Backenstrass M, Jaentsch B, Kaiser S, Roth A, Unger J, Weisbrod $M$, Renneberg B. Response inhibition in borderline personality disorder: performance in a go/Nogo task. Psychopathology. 2008;41:50-7.

18. ten Have $M$, van Dorsselaer $S$, de Graaf R. The association between type and number of adverse working conditions and mental health during a time of economic crisis (2010-2012). Soc Psychiatry Psychiatr Epidemiol. 2015;50: 899-907. Available from: https://doi.org/10.1007/s00127-015-1009-2. Springer Berlin Heidelberg 
19. Hengartner MP, Müller M, Rodgers S, Rössler W, Ajdacic-Gross V Interpersonal functioning deficits in association with DSM-IV personality disorder dimensions. Soc Psychiatry Psychiatr Epidemiol. 2013;49:317-25.

20. Coid J, Yang M, Beppington P, Moran P, Brugha T, Jenkins R, Farrell M, Singleton N. Borderline personality disorder: health service use and social functioning among a national household population. Psychol Med. 2009;39: $1721-31$.

21. American Psychiatric Association. Diagnostic and Statistical Manual of Mental Disorders: DSM-5. 2013. Washington, D.C. 5th edition.

22. de Graaf $R$, ten Have M, van Dorsselaer $S$. The Netherlands Mental Health Survey and Incidence Study-2 (NEMESIS-2): design and methods. Int J Methods Psychiatr Res. 2010;19:125-41.

23. Loranger, A. W., Janca, A., Sartorius N. The ICD-10 international personality disorder examination (IPDE). 1st ed. Cambridge; New York; Melbourne; Madrid; cape town; Singapore; Sao Paulo: Cambridge University Press; 1997.

24. Moffitt TE, Caspi A, Taylor A, Kokaua J, Milne BJ, Polanczyk G, Poulton R. How common are common mental disorders? Evidence that lifetime prevalence rates are doubled by prospective versus retrospective ascertainment. Psychol Med. 2010;40:899-909.

25. De Graaf R, Van Dorsselaer S, Tuithof M, Ten Have M. Sociodemographic and psychiatric predictors of attrition in a prospective psychiatric epidemiological study among the general population. Result of the Netherlands Mental Health Survey and Incidence Study-2. Compr Psychiatry. 2013;54:1131-1139. Available from: https://doi.org/10.1016/j.comppsych. 2013.05.012. Elsevier Inc.

26. Kessler RC. Üstün TB. The world mental health $(\mathrm{WMH})$ survey initiative version of the World Health Organization (WHO) composite international diagnostic interview (CIDI). Int J Methods Psychiatr Res. 2004;13:93-121.

27. Karasek R, Brisson C, Kawakami N, Houtman I, Bongers P, Amick B. The job content questionnaire (JCQ): an instrument for internationally comparative assessments of psychosocial job characteristics. J Occup Health Psychol. 1998;:322-55

28. Butterworth P, Leach LS, McManus S, Stansfeld SA. Common mental disorders, unemployment and psychosocial job quality: is a poor job better than no job at all? Psychol Med. 2013:43:1763-72. Available from: http://www.ncbi.nlm.nih.gov/pubmed/23190443

29. Chwastiak LA, Von Korff M. Disability in depression and back pain evaluation of the World Health Organization disability assessment schedule (WHO DAS II) in a primary care setting. J Clin Epidemiol. 2003;56:507-14.

30. Kessler RC, Greenberg PE, Mickelson KD, Meneades LM, Wang PS. The effects of chronic medical conditions on work loss and work cutback. J Occup Environ Med. 2001:43:218-25.

31. de Graaf R, Kessler RC, Fayyad J, ten Have M, Alonso J, Angermeyer M, Borges G, Demyttenaere K, Gasquet I, de Girolamo G, Haro JM, Jin R, Karam EG, Ormel J, Posada-Villa J. The prevalence and effects of adult attentiondeficit/hyperactivity disorder (ADHD) on the performance of workers: results from the WHO World Mental Health Survey Initiative. Occup Environ Med. 2008:65:835-42

32. Haro JM, Arbabzadeh-Bouchez S, Brugha TS, Girolamo de G, Guyer ME, Jin R, Lepine JP, Mazzi F, Reneses B, Vilagut G, Sampson NA, Kessler RC. Concordance of the Composite International Diagnostic Interview Version 3. 0 (CIDI 3.0) with standardized clinical assessments in the WHO World Mental Health Surveys. Int J Methods Psychiatr Res. 2006;15:167-80.

33. Skinner CJ, Holt D, Smith T. Analysis of complex surveys: Wiley; 1989

34. Ebner-Priemer UW, Kuo J, Schlotz W, Kleindienst N, Rosenthal MZ, Dettere L, Linehan MM, Bohus M. Distress and Affective Dysregulation in Patients With Borderline Personality Disorder. J Nerv Ment Dis. 2008;196:314-20.

35. Tyrer P, Reed GM, Crawford MJ. Classification, assessment, prevalence, and effect of personality disorder. Lancet. 2015;385:717-26.

\section{Ready to submit your research? Choose BMC and benefit from:}

- fast, convenient online submission

- thorough peer review by experienced researchers in your field

- rapid publication on acceptance

- support for research data, including large and complex data types

- gold Open Access which fosters wider collaboration and increased citations

- maximum visibility for your research: over $100 \mathrm{M}$ website views per year

At BMC, research is always in progress.

Learn more biomedcentral.com/submissions 